\title{
TENSÃO ENTRE PROPRIEDADE PRIVADA E MEIO AMBIENTE À LUZ DA
}

\author{
MULTIPOLARIDADE
}

\author{
TENSION AMONG PRIVATE PROPERTY AND ENVIRONMENT UNDER THE ASPECT OF \\ MULTIPOLARITY
}

Giselle Marques Araujo. ${ }^{1}$

Resumo: O objetivo deste artigo é investigar em que medida o direito de propriedade vem sendo atingido pelo processo de constitucionalização, em especial verificando se poderia continuar a ser considerado um "direito fundamental", já que frontalmente atingido pela obrigatoriedade de atender à função social e ambiental. A reflexão se desenvolve sob o referencial teórico da Teoria Geral dos Direitos Fundamentais, trazendo à luz a proposta de ponderação na perspectiva multipolar elaborada por Christian Calliess, que destaca a proteção ambiental como verdadeira condição de legitimidade do Estado de Direito. A conclusão é no sentido de que a propriedade continua a ser um direito fundamental, porém apresentando atualmente um novo perfil ambientalmente qualificado, no qual a intervenção do Estado em favor da sociedade e do ambiente pode e deve ocorrer, porém adstrita a limitar o mínimo possível os direitos de liberdade. O artigo apresenta, ainda, estudos acerca de como as constituições de outros países, em especial da Alemanha, tratam a questão da proteção ambiental.

Palavras-chave: Constitucionalismo. Direitos fundamentais; Propriedade privada. Meio ambiente.

Abstract: The objective of this paper is to investigate to what extent the right to property has been hit by the constitutional process, in particular checking if it could still be considered a "fundamental right" since frontally hit by the obligation to meet the social and environmental function. The reflection is developed under the theoretical framework of the General Theory of Fundamental Rights, bringing to light the proposed weighting in the multipolar perspective elaborated by Christian Calliess, highlighting environmental protection as true condition of the rule of law legitimacy. The conclusion is towards the continuation of property as a fundamental right, but currently presenting a new environmentally qualified profile, in which state intervention in favor of society and the environment can and does occur, but enrolled to limit the minimum possible the rights of freedom. The article also presents studies on how the constitutions of other countries treat the issue of environmental protection.

\footnotetext{
${ }^{1}$ Advogada. Doutora em Direito pela Universidade Veiga de Almeida. Mestre em Direito pela Universidade Gama Filho; Professora Titular de Direito Civil da Universidade Católica Dom Bosco. Ex-bolsista Nota 10 da FAPERJ.
}

Artigo recebido em 05/03/2017 e aprovado para publicação em 19/02/2019. 


\section{RFD}

Keywords: Constitutionalism. Fundamental rights. Private property. Environment.

\section{INTRODUÇÃO}

O fenômeno da constitucionalização vem atingindo institutos do direito privado, de modo a desenhá-los em um novo perfil. O objetivo deste artigo é investigar em que medida o direito de propriedade foi atingido pelo processo de constitucionalização: o direito de propriedade poderia continuar a ser considerado um "direito fundamental", eis que gravado dos ônus decorrentes do dever de atender à função social e ambiental? Para responder a essa importante indagação, parte-se de critérios para identificar os direitos fundamentais. ${ }^{2}$

A hipótese que ora se propõe é no sentido de que a propriedade privada continua a ser um direito fundamental, porém apresentando novo conteúdo, no qual sobressaem as funções social e ambiental. Para verificá-la será utilizado o referencial teórico oferecido pela Teoria Geral dos Direitos Fundamentais, a partir do estudo comparado das experiências constitucionais de outros países, em especial a alemã, apreciada à luz do referencial teórico desenvolvido por Calliess ${ }^{3}$ (2001, p. 18-23) que traduz uma análise da tensão efetiva e potencial entre a proteção ambiental e a proteção aos direitos fundamentais enquanto função central do Estado de Direito.

Recentemente a doutrina alemã passou a estudar aspectos constitucionais envolvendo a colisão entre direitos fundamentais. No que diz respeito à tensão entre propriedade privada e meio ambiente (cerne do presente artigo), a partir do ano de 1994, quando a lei fundamental alemã acolheu no artigo 20a uma norma objetiva de proteção ambiental, vem sendo amadurecido o debate acerca da seguinte questão: se a proteção do ambiente é alçada a objetivo fundamental que orienta todo o ordenamento - não de forma exclusiva, mas em conjunto com os princípios da dignidade humana, do Estado de Direito e do Estado Social -

\footnotetext{
${ }^{2}$ Há aqueles que defendam como critério para identificar os direitos fundamentais a menção expressa a esta condição feita pela própria Constituição, o que a primeira vista apresenta-se como um caminho seguro (dentre estes, Lorenzo Martín-Retortillo, na obra Regimen constitucional de los derechos fundamentales (1988, p. 65); e Konrad Hesse, no clássico Elementos de direito constitucional da República Federal da Alemanha (1998, p. 225); mas por outro lado pode significar um "engessamento" reduzir a noção de direitos fundamentais a um mero critério formal, ainda que fornecido pela própria Carta Magna. Compartilham desta opinião, Ingo Wolfgang Sarlet (2001, p. 97) e Flávia Piovesan (1997, p. 78-80).

${ }^{3}$ Christian Calliess é professor da Universidade Livre de Berlim e da pós-graduação sobre a integração europeia do Instituto Europeu da Universidade de Saarland. Membro do Conselho Consultivo do Meio Ambiente (SRU); o foco do seu trabalho científico é a política ambiental no âmbito da lei europeia e os direitos humanos fundamentais (incluindo os direitos de proteção).
} 


\section{RFD}

, seria possível conciliá-la com os direitos fundamentais de modo a evitar que estes sejam excessivamente restringidos em nome do interesse ambiental?

A resposta a essa questão pode ser construída a partir de diferentes perspectivas. A proposta oferecida por Calliess surge como inovadora, na medida em que indica como solução a superação da bipolaridade no que diz respeito à colisão de direitos fundamentais, em favor de um raciocínio mais amplo, de multipolaridade. Por isso o pensamento deste autor é importante, e será objeto do presente estudo.

Ao analisar o disposto no artigo $20^{\mathrm{a}}$ da Lei Federal Alemã, Calliess defende que tal dispositivo obriga o legislador à produção de normas de proteção ambiental, permitindo o controle judicial relativo à proibição de proteção deficiente, na mesma linha da perspectiva objetiva dos direitos fundamentais da formulação de Claus-Wilhelm Canaris para os deveres de proteção. Assim, em um mesmo caso concreto incidem a proteção dos direitos fundamentais na perspectiva subjetiva - posição subjetiva, geralmente uma obrigação de abstenção face ao Estado - e na perspectiva objetiva - deveres de proteção que dependem da atuação estatal. Segundo essa proposta, as colisões não são mais bipolares, mas sim multipolares.

A formulação de Calliess está direcionada para a análise da tensão efetiva e potencial entre a proteção ambiental e a proteção dos direitos fundamentais, compreendidos como função central do Estado de Direito. Essa tensão verifica-se em situações nas quais a proteção ambiental colide com os direitos fundamentais, como o direito de propriedade. O Estado de Direito está, portanto, em posição delicada: deve, no cumprimento de sua responsabilidade estatal pela proteção ambiental em meio a medidas restritivas e realizadoras da liberdade, efetivar uma ponderação que seja o mais protetora possível da liberdade. Essa dupla tarefa do agir estatal no âmbito da proteção ambiental conduziria a um "déficit de Estado de Direito"?

Para responder a essa questão, Calliess coloca a proteção ambiental como condição de legitimidade do Estado, significando que este talvez não esteja obrigado a garantir absoluta segurança no âmbito de uma tarefa de otimização ecológica, mas sim a tomar o devido cuidado para que riscos de dano aos bens individuais fundamentais não se tornem tão grandes a ponto de transformarem-se em um perigo no sentido jurídico. Aqui, o "Estado de Direito" deve prestar atenção ao fato de que deve coordenar as esferas de direito dos cidadãos em função de uma máxima liberdade possível. Desta forma, concepções que poderiam 
resultar em uma "Ecoditadura", estariam afastadas. Nesse diapasão, pretende-se analisar a tensão entre direito de propriedade, enquanto direito de liberdade, em face do direito ao meio ambiente ecologicamente equilibrado, contextualizando tal reflexão no âmbito do processo de constitucionalização do direito privado.

\section{A CONSTITUCIONALIZAÇÃO DO DIREITO PRIVADO}

O que é a constitucionalização do direito privado? Ela, de fato, existe? Este é um debate que ainda não alcançou a unanimidade, especialmente no Brasil. Capanema ${ }^{4}$ e quase toda a doutrina paulista, e, no Rio de Janeiro, o professor Ricardo Lira, posicionaram-se no sentido de que não houve a "constitucionalização do Direito Civil", dentre outros motivos porque, segundo eles, a Lei de Introdução ao Código Civil, que é de 04 de setembro de 1942, já previa grande parte dos princípios que foram abraçados pela Constituição de 1988.

Ainda assim, é inegável que houve recentemente uma mudança de enfoque. Outrora as normas constitucionais dirigiam-se não diretamente aos cidadãos, mas ao legislador infraconstitucional, funcionando como limites à atuação do Estado. Acreditava-se que as relações entre particulares eram estabelecidas e tuteladas pelo Código Civil, sem nenhum influxo das normas constitucionais. A interferência do Estado no âmbito das relações privadas era admitida apenas para "manter a coexistência pacífica entre as esferas individuais", conforme a lição de Costa (2005, p. 63).

O século XIX inaugurou mudanças significativas em decorrência da industrialização, e as demandas sociais passaram a exigir a intervenção do Estado na economia. Especialmente após a Segunda Grande Guerra, surgiram as grandes constituições democráticas permeadas por valores sociais que substituíram os liberais. O individualismo cedeu lugar ao solidarismo, inserindo uma nova tábua de valores na qual a Constituição deixou de ser vista apenas como depositária de "normas programáticas", reclamando-se o reconhecimento de sua "força normativa". Este movimento vem resultando em uma nova personalização dos institutos civis.

\footnotetext{
${ }^{4}$ A posição de Sylvio Capanema de Souza foi externada em palestra por ele proferida, intitulada "Contrato, titularidade e família: da codificação a constitucionalização", em evento organizado pela CEPAD, sob a coordenação do professor desembargador Sérgio Cavalieri Filho, no dia 02 mai. 2005. Disponível em: $<$ http://aulascivil constitucional.blogspot.com.br>. Acesso em: 20 jul. 2012.
} 
A dicotomia entre o direito público e o privado vem sendo relativizada, conforme apontou Trabucchi (1973, p. 9), defendendo que a distinção não vem em uma linha reta e constante, estando sujeita a mudanças no tempo e no espaço, segundo tendências sociais e políticas. Perlingieri (1997, p. 183) chegou até mesmo a sugerir a unificação das duas áreas do Direito, tendo como sustentáculo a Constituição, que passaria a regular diretamente as relações privadas. Raiser (1990, p. 32), por sua vez, propôs a visão deste fenômeno jurídico a partir de dois focos centrais de força normativa, distintos, mas não estanques entre si, sugerindo a imagem de uma única elipse, com dois polos de irradiação distintos, o público e o privado, um em cada extremidade. A esse respeito, Barroso (2010, p. 60) assevera:

O debate jurídico e filosófico da atualidade deslocou-se da diferenciação formal entre direito público e direito privado para uma discussão mais ampla, complexa e sutil acerca das esferas pública e privada na vida dos povos e das instituições. A percepção da existência de um espaço privado e de um espaço público na vida do homem remonta à Antiguidade, no mínimo ao advento da polis grega. Aristóteles já afirmava a diferença de natureza entre a cidade, esfera pública, e a família, esfera privada. A demarcação desses dois domínios tem variado desde então, no tempo e no espaço, com momentos de quase desaparecimento do espaço público e outros que em sua expansão opressiva praticamente suprimiu valores tradicionais da vida privada. As constituições modernas influenciam e sofrem a influência dessa dicotomia, que guarda, no entanto, algumas dimensões metajurídicas, isto é, fora do alcance do Direito. O tema merece uma reflexão interdisciplinar.

Na história do Direito, houve quase sempre concordância dos juristas no sentido de que os princípios constitucionais estão no topo da pirâmide. Nunca se duvidou disso. Entretanto, o que mudou a partir do fenômeno do constitucionalismo foi o caráter que se atribui a estes princípios. Há até bem pouco tempo, a eles era atribuída uma função quase utópica, no sentido de que constituiriam ideais a serem buscados; porém, situados no campo do "dever ser", muito longe de ser alcançados. ${ }^{5}$ Já o Direito Civil parecia oferecer caminhos mais seguros, instrumentos para a realização daquilo que "é".

Apenas recentemente é que, conforme afirma Moraes (1993, p. 29), “a norma constitucional assume, no Direito Civil, a função de, validando a norma ordinária aplicável

\footnotetext{
${ }^{5} \mathrm{O}$ debate acerca da efetividade dos princípios constitucionais, no Brasil, aconteceu concomitante ao processo de amadurecimento da Constituição de 1988, pois, no momento que sucedeu à promulgação da Constituição que ora completa vinte e oito anos, a finalidade dos princípios tanto na visão dos doutrinadores quanto na dos tribunais era a de "orientar", ou de "programar" as ações do Estado. Careciam tais princípios de força normativa. Conforme asseverou Barroso (1994, p. 30-60), "não é próprio das normas jurídicas - e, ipso facto, das normas constitucionais - sugerir, aconselhar, alvitrar. São elas comandos imperativos. O resgate da imperatividade do texto constitucional, por óbvio que possa parecer, é uma instigante novidade neste país habituado a maltratar suas instituições".
} 
no caso concreto, modificar, à luz de seus valores e princípios, os institutos tradicionais".

Dentre estes, está o direito de propriedade, que atualmente deve ser visto em consonância com um sistema de valores no qual a dignidade da pessoa humana, a solidariedade social e o respeito ao meio ambiente adquirem relevância, conforme será tratado na seção a seguir.

Sarmento (2003, p. 273) argumenta que a noção de que a Constituição é uma norma jurídica, dotada de caráter imperativo, cujos comandos podem ser tutelados em juízo quando não forem espontaneamente respeitados, embora possa parecer uma completa obviedade, demorou algum tempo para se firmar. Na atualidade, a força normativa da Constituição não mais pode ser afastada, de modo que os institutos tradicionais do Direito Civil devem ser redesenhados. É o caso do direito de propriedade, instituto do direito civil sobre os influxos dos imperativos constitucionais, como é o caso do direito ao meio ambiente ecologicamente equilibrado, proclamado no caput artigo 225 da Constituição brasileira.

\section{O DIREITO AO MEIO AMBIENTE ECOLOGICAMENTE EQUILIBRADO NO ÂMBITO DA TEORIA GERAL DOS DIREITOS FUNDAMENTAIS}

No caso brasileiro, os direitos fundamentais estão em sua quase totalidade enumerados no artigo $5^{\circ}$ da Constituição, em vigor desde 1988. O direito ao meio ambiente equilibrado, no entanto, não consta neste rol, estando insculpido no artigo 225. Segundo Derani (1988, p. 91), isso não significa que deva ser desconsiderado, "pois um direito é fundamental quando o seu conteúdo invoca a liberdade do ser humano".

A clássica obra "A Era dos Direitos" de Norberto Bobbio é referência obrigatória quando se pretende compreender os direitos fundamentais. ${ }^{6}$ Segundo o autor (1992, p. 5), os direitos do homem, por mais fundamentais que sejam, são históricos, nascidos sob determinadas circunstâncias, "caracterizados por lutas em defesa de novas liberdades contra

\footnotetext{
${ }^{6}$ Não são poucas as críticas à formulação das "gerações" de direitos fundamentais propostas por Bobbio. A esse respeito, Trindade (2003, p. 41) opõe-se ao que chamou de "visão fragmentária dos direitos humanos", defendendo a "natureza complementar" de todos os direitos humanos, com o que concordou Sarlet (2013, p. 31). Em que pese a sabedoria reconhecida dos autores que compartilham dessa visão, no entanto, discorda-se desse entendimento, na medida em que Bobbio não defendeu que uma geração de direitos revogaria ou excluiria a outra. Ao identificar as "gerações de direitos humanos", Bobbio pretendeu ilustrar como aconteceu o surgimento de cada classe dos direitos humanos, de acordo com cada momento histórico. A teoria de Bobbio não propôs a divisibilidade dos direitos humanos, ou a hierarquia entre eles, como equivocadamente entendem alguns autores. Seu pensamento contribuiu sobremaneira para que se pudesse, de forma didática, vislumbrar o surgimento e a positivação dos direitos humanos, como decorrência da luta de "novos direitos" contra "velhos poderes".
} 
velhos poderes, e nascidos de modo gradual, não todos de uma vez, e nem de uma vez por todas".

O direito de propriedade em uma primeira fase de seu desenvolvimento histórico fundamentava-se na necessidade do indivíduo em usufruir de uma liberdade negativa, consubstanciada na não intervenção do Estado na esfera individual, classificado por Bobbio como "direito de primeira geração", nascido da luta dos parlamentos contra os soberanos absolutos. As liberdades políticas e sociais, por sua vez, na visão de Bobbio, seriam resultado do nascimento, crescimento e amadurecimento do movimento dos trabalhadores assalariados, "dos camponeses com pouca ou nenhuma terra", que passaram a exigir do Estado "não só o reconhecimento da liberdade pessoal e das liberdades negativas", mas também “a proteção do trabalho contra o desemprego", o direito à educação, à saúde, enfim, os direitos sociais, classificados por Bobbio como "de segunda geração". Ao lado destes, emergiram os direitos de terceira geração, os quais:

[...] constituem uma categoria, para dizer a verdade, ainda excessivamente heterogênea e vaga, o que nos impede compreender do que efetivamente se trata. O mais importante deles é o reivindicado pelos movimentos ecológicos: o direito de viver num ambiente não poluído. (BOBBIO, 1992, p. 6)

É em face desta incerteza quanto ao conteúdo do direito ao meio ambiente ecologicamente equilibrado e seus reflexos no âmbito da propriedade que se desenvolve este artigo, com o objetivo de contribuir para a compreensão deste fenômeno, acerca do qual as teorias existentes são ainda insuficientes, a despeito do fato de que a consciência ecológica avança a passos largos, estando presente hoje no arcabouço legislativo da maioria dos países ocidentais. Sarlet (2008, p. 50-51) identifica o direito ao ambiente equilibrado dentre os direitos fundamentais que classificou como de "terceira dimensão":

Os direitos fundamentais de terceira dimensão, também denominados direitos de fraternidade ou de solidariedade, trazem como nota distintiva o fato de se desprenderem, em princípio, da figura do homem indivíduo como seu titular, destinando-se à proteção de grupos humanos (família, povo, nação), caracterizandose, consequentemente, como direitos de titularidade coletiva ou difusa.

Algumas constituições incluem o direito ao meio ambiente ecologicamente equilibrado no rol dos direitos fundamentais. Na Europa, a Conferência das Nações Unidas sobre o meio ambiente que aconteceu em Estocolmo (Suécia) no ano de 1972 influenciou 
decisivamente as constituições dos povos que se libertavam de regimes ditatoriais, como é o caso da Espanha e de Portugal. A Constituição da República Portuguesa de 1976, no artigo 66, inseriu dentre os direitos econômicos, sociais e culturais "o direito a um ambiente de vida humano, sadio e ecologicamente equilibrado". Inspirada nesse dispositivo, a Constituição da Espanha em 1978 disciplinou no artigo 45: ${ }^{7}$

1) Todos têm o direito de desfrutar de um meio ambiente adequado para o desenvolvimento da pessoa, assim como o dever de conservá-lo; 2) Os poderes públicos devem assegurar o uso racional dos recursos naturais com a finalidade de proteger e melhorar a qualidade de vida, defender e restaurar o meio ambiente, contando com a inescusável solidariedade coletiva; 3) Para aqueles que violarem o disposto nos itens anteriores, nos termos da lei serão estabelecidas sanções penais ou, conforme o caso, administrativas, assim como a obrigação de reparar o dano causado.

No caso da Alemanha, após a Conferência de Estocolmo, intensos debates doutrinários ocorreram sobre a necessidade de incorporar o direito ao meio ambiente sadio no âmbito constitucional. Apesar disso, somente em 1994 a Lei Fundamental acolheu o artigo 20a, cujo teor é o seguinte: ${ }^{8}$

O Estado deve proteger as bases naturais da vida, tendo em conta também a sua responsabilidade para com as futuras gerações, no âmbito da ordem constitucional, segundo a lei e o Direito, por meio do poder Legislativo, e dos poderes Executivo e Judiciário.

A Lei Fundamental Alemã, portanto, atribuiu ao Estado o dever de proteção ao meio ambiente, ao invés de instituir um direito fundamental ao ambiente. Ainda assim, a doutrina daquele país atribui peso considerável ao referido princípio. É o caso do Professor Christian Calliess, para quem esse dispositivo constitucional, na medida em que vinculou o legislador à produção de normas de proteção ambiental, permitiu o controle judicial em face da

\footnotetext{
${ }^{7}$ Tradução livre da autora. Texto original: 1) Todos tienen el derecho a disfrutar de un medio ambiente adecuado para el desarrollo de la persona, así como el deber de conservalo; 2) Los poderes públicos velarán por la utilización racional de todos los recursos naturales, con el fin de proteger y mejorar la calidad de vida y defender y restaurar el medio ambiente, apoyándose em la inexcusable solidariedad colectiva; 3) Para quienes violen lo dispuesto en el apartado anterior, en los términos que la ley fije se establecerán sanciones penales o, en su caso, administrativas, así como la obligación de reparar el daño causado.

${ }^{8}$ Em tradução livre da autora. A versão original: "Der Staat schützt auch in Verantwortung für die künftigen Generationen die natürlichen Lebensgrundlagen im Rahmen der verfassungsmäßigen Ordnung durch die Gesetzgebung und nach Maßgabe von Gesetz und Recht durch die vollziehende Gewalt und die Rechtsprechung." Disponível em: <http://www.gesetze-im-internet.de/bundesrecht/gg/gesamt.pdf>. Acesso em: 10 out. 2013.
} 


\section{RFD}

proibição de proteção deficiente, à semelhança da perspectiva objetiva dos direitos fundamentais, e em consonância com a formulação de Canaris (2009, p. 36). ${ }^{9}$

A obra de Christian Calliess apresenta uma análise da tensão efetiva e potencial entre a proteção ambiental e a proteção aos direitos fundamentais, que seria a função central do Estado de Direito. Essa tensão verifica-se em situações nas quais a proteção ambiental colide com outros direitos fundamentais, como o direito de propriedade, que é também o núcleo central do presente artigo. Por isso, a reflexão de Calliess pode ser utilizada para verificar se o direito ao meio ambiente ecologicamente equilibrado constitui-se em um "direito fundamental".

Ainda que no caso da Alemanha o direito ao meio ambiente ecologicamente equilibrado não esteja entre os direitos fundamentais, Calliess (2001, p. 29) defende que a proteção ambiental é atualmente condição de legitimidade ${ }^{10}$ do Estado. Por isso, o Estado deve tomar o devido cuidado para que os riscos de dano aos bens individuais fundamentais não se tornem tão grandes a ponto de transformarem-se em um perigo no sentido jurídico. Ao Estado de Direito, segundo este autor, cabe se atentar ao fato de que deve coordenar as esferas de direito dos cidadãos em função de uma máxima liberdade possível, afastando as concepções que possam resultar em uma "ecoditadura".

Em outras palavras, a tarefa de proteção ambiental que o artigo 20a da Lei Fundamental Alemã atribuiu ao Estado não pode significar um "déficit de Estado de Direito". Como efetivar isso? Calliess propõe que o Estado, em meio a medidas restritivas e garantidoras da liberdade, realize uma ponderação o mais protetora possível da liberdade e com isso digna de um verdadeiro Estado de Direito.

A ponderação proposta por Calliess vai muito além das discussões sobre colisão entre direitos fundamentais que se tornaram bastantes conhecidas no Brasil a partir das contribuições de Alexy e Dworkin. A colisão entre princípios constitui-se em um dos grandes desafios para o direito constitucional contemporâneo. A chave para a solução deste problema, segundo Alexy (2008, p. 85), estaria na análise da estrutura das normas de direitos fundamentais, buscando-se

\footnotetext{
${ }^{9}$ Claus-Wilhelm Canaris é um jurista alemão considerado um dos mais importantes dogmáticos do Direito Civil. Antecedeu Karl Larenz na Cátedra de Direito Civil e Filosofia do Direito da Universidade Ludwig-Maximilians, em Munique. Tratando da questão da eficácia dos direitos fundamentais no direito privado, propôs um modelo dogmático fundamentado na distinção entre a função dos direitos fundamentais como proibições de intervenção e como imperativos de tutela.

${ }^{10}$ A legitimidade é destacada aqui como um elemento externo ao sistema, mas que o justifica. Nino (1994, p. 62) argumenta que "a validez de certo ordenamento jurídico não pode fundar-se em regras desse mesmo sistema jurídico, mas deve derivar de princípios externos ao próprio sistema".
} 
a distinção entre princípios e regras. No caso de conflito entre regras, seria possível aplicar uma "cláusula de exceção" a uma delas, ou até mesmo a invalidação daquela que tivesse menor incidência na análise de um caso concreto. A distinção entre princípios, no entanto, não pode resultar na invalidação ou revogação de quaisquer destes. Um princípio nunca revoga ou invalida o outro. Com base nessa linha de raciocínio, Alexy propõe uma fórmula através da qual seriam atribuídos pelo intérprete valores baseados no peso de cada princípio, segundo as características de incidência destes no caso concreto. Haveria dois métodos para a solução de conflitos, a ponderação e o balanceamento. Alexy desenvolve a proposta da ponderação como alternativa ao método da subsunção para a interpretação e aplicação do Direito. Dworkin (1978, p. 40-42), enfrentando a questão da diferença entre princípios e regras, afirma que os primeiros possuem uma dimensão de peso ou importância que as segundas não têm, de modo que, em caso de colisão, o que tiver maior peso de incidência naquele caso concreto, sobrepor-se-á ao outro que, no entanto, não perderá a sua validade, apenas se afastará momentaneamente, a fim de que o princípio mais adequado àquele caso concreto possa incidir com maior amplitude.

Calliess, por sua vez, argumenta que as colisões não devem mais ser bipolares, mas sim "multipolares". E é nessa perspectiva que, mesmo sem a inserção expressa do direito ao ambiente no catálogo dos direitos fundamentais na Alemanha, seria possível naquele sistema jurídico a identificação de um "Estado Ambiental", termo que evidencia a necessidade de considerar o divisor de águas no qual se encontra o Estado de Direito em relação à tensão entre proteção ambiental e garantia de outros direitos fundamentais, dentre os quais está o direito de propriedade.

Considerando-se que a atividade humana quase sempre implicará na alteração das condições naturais, o foco do "Estado Ambiental" estaria nos critérios de definição para melhores condições ambientais, dentre os quais Calliess destaca o princípio da precaução e o postulado do desenvolvimento sustentável. Essas seriam diretrizes a serem também observadas na interpretação judicial das questões que envolvem o meio ambiente. O Estado, portanto, tem a tarefa de não deixar o desenvolvimento seguir livremente em uma época na qual o avanço tecnológico caminha a passos largos, e sim de dar direção a esse desenvolvimento. Deste poder-dever do Estado resultaria um duplo monopólio da força estatal, de modo que os deveres de proteção ambiental do Estado fixados pelo artigo 20a da Lei Fundamental Alemã estariam fortalecidos a ponto de ser colocados em igual força em relação aos direitos fundamentais na perspectiva subjetiva individual. 
Os interesses de direito subjetivo e objetivo seriam em um primeiro momento realizados na dimensão de defesa dos direitos fundamentais dos indivíduos subjetivamente protegidos; no segundo momento, pela dimensão dos deveres de proteção decorrentes de direitos fundamentais no caso dos interessados. No terceiro momento, pelo interesse comum de proteção ambiental pelo Estado, conforme disciplinado no artigo 20a. Esses interesses não poderiam ser tratados de forma isolada, e sim conjuntamente, dentro de uma perspectiva de ponderação, na linha da concepção de Robert Alexy. Para além da fórmula da ponderação de Alexy, no entanto, a proposta de Calliess é desenvolver um exercício de proporcionalidade que seja multipolar para solucionar os casos concretos que surgem quando se articula um Estado Ambiental em um Estado de Direito.

Assim, mesmo sem o reconhecimento expresso da Lei Fundamental Alemã quanto ao direito ao meio ambiente ecologicamente equilibrado como um direito fundamental, a doutrina naquele país expressa a proteção ambiental como condição de legitimidade do Estado de Direito. O que dizer, então, dos países nos quais as constituições vigentes incluíram o direito ao meio ambiente saudável no rol dos direitos fundamentais, como é o caso do Brasil? Não são poucas as vozes que o afirmam como direito fundamental. Canotilho e Moreira (1993, p. 37) dizem que o direito ao meio ambiente é um dos "novos direitos fundamentais". Raposo (1994, p. 15) o considera "direito da personalidade e, simultaneamente, um direito e uma garantia constitucional". Prieur (2004, p. 23) avança no sentido de dizer que a proteção do ambiente não está ligada ao non facere do Estado, mas, ao contrário, exige prestações positivas em reforço aos deveres infraconstitucionais de garantia pelas autoridades públicas dos processos ecológicos essenciais. A inclusão do direito ao meio ambiente equilibrado no rol dos direitos fundamentais traz consigo avanços que vão muito além de um abstrato impacto político e moral, podendo resultar em benefícios significativos no relacionamento do ser humano com a natureza.

\section{O DIREITO DE PROPRIEDADE ENQUANTO GARANTIA CONSTITUCIONAL}

$\mathrm{Na}$ seção anterior ficou claro que o direito ao meio ambiente ecologicamente equilibrado tem sido considerado nas constituições democráticas modernas como um direito fundamental. E, mesmo nos casos em que não alcança este status - como a Alemanha cuja Lei Fundamental atribuiu ao Estado o dever de proteger o meio ambiente, ao invés de instituir 
um direito fundamental ao ambiente -, tal dever do Estado estaria fortalecido a ponto de ser colocado em igual força em relação aos direitos fundamentais na perspectiva subjetiva individual. Contudo, neste novo momento em que o direito ao ambiente exsurge como direito fundamental, o direito de propriedade continuaria a ser um direito fundamental?

O direito de propriedade foi apontado por Rodotà (1990, p. 22) como um "direito terrível", por ser de exclusão, exercido por um ou alguns dos membros integrantes da sociedade contra os demais (rectius: erga omnes). Por essa razão, atua como elemento propulsor das desigualdades sociais. Seria necessário, portanto, questionar se o acesso à cidadania social ocorreria através da propriedade ou dos demais direitos. O direito de propriedade se desdobraria, não podendo mais significar apenas um direito a não intervenção estatal ou de terceiros, mas passando a traduzir-se em um direito enquanto instrumento de efetivação da cidadania do indivíduo.

A ideia de exclusão dos demais sujeitos de direito de qualquer relação com a coisa assume lugar destacado nas definições de propriedade do Código Civil alemão. ${ }^{11}$ Não se pode olvidar, por outro lado, que inúmeras declarações de direitos humanos reconhecem o direito de propriedade como um direito fundamental. O artigo 17 da Declaração de direitos do homem e do cidadão de 1789 proclamou: "Como a propriedade é um direito inviolável e sagrado, ninguém dela pode ser privado, a não ser quando a necessidade pública legalmente comprovada o exigir e sob condição de justa e prévia indenização”. A Declaração Universal dos Direitos Humanos de 1948, de seu turno, declarou que "todo ser humano tem direito à propriedade, só ou em sociedade com outros" e, ainda que "ninguém será arbitrariamente privado de sua propriedade".

Os direitos humanos compreendem, no entanto, um lado passivo. Falar deles deve significar também a clara noção de que há deveres humanos. O direito de propriedade, nesse diapasão, compreende também deveres (dentre os quais está a função social e a ambiental). Nesse sentido, é o disposto no art. 14, segunda alínea, da Lei Fundamental de Bonn: A propriedade implica em obrigações. Seu uso deve servir, por igual, ao bem-estar da coletividade (Eigentum verpflichtet. Sein Gebrauch soll zugleich dem Wohle der Allgemeiheit dienen). Assim, o dever de atender à função ambiental não se trata de uma diretriz à

\footnotetext{
11 (§ 903: Der Eigentümer einer Sache kann, soweit nicht das Gesetz oder Rechte Dritter entgegenstehen, mit der Sache nach Belieben verfahrem und andere von jeder Einwirkung ausschliessen) European Law. German Law Journal, v. 10, n. 10, p. 1367-1382, 2009. RAO, Pemmaraju Sreenivasa. Multiple.
} 


\title{
RFD
}

legislação, ao titular da propriedade privada e aos tribunais, mas, sim, de vinculação jurídica efetiva, tanto do Estado quanto dos particulares.

O descumprimento dos deveres inerentes ao direito de propriedade pode resultar até mesmo na desapropriação por interesse social (e ambiental), podendo inclusive implicar na inexistência de indenização por parte do Estado, ou indenização abaixo do valor de mercado, como aduz Comparato:

\begin{abstract}
Instrumento clássico para a realização da política de redistribuição de propriedades é a desapropriação por interesse social. Ora, essa espécie de expropriação não representa o sacrifício de um direito individual às exigências de necessidade ou utilidade pública patrimonial. Ela constitui, na verdade, a imposição administrativa de uma sanção, pelo descumprimento do dever, que incumbe a todo proprietário, de dar a certos e determinados bens uma destinação social. Por isso mesmo, é antijurídico atribuir ao expropriado, em tal caso, uma indenização completa, correspondente ao valor venal do bem, mais juros compensatórios, como se não tivesse havido abuso do direito de propriedade. A Constituição, aliás, tanto no art. $5^{\circ}-$ XXIV quanto no art. 182 , $\S 3^{\circ} \mathrm{e}$ no art. 184 , não fala em indenização pelo valor de mercado, mas sim em justa indenização, o que é bem diferente. A justiça indenizatória, no caso, é obviamente uma regra de proporcionalidade, ou seja, adaptação da decisão jurídica às circunstâncias de cada caso. Ressarcir integralmente aquele que descumpre o seu dever fundamental de proprietário é proceder com manifesta injustiça, premiando o abuso.
\end{abstract}

O direito de propriedade precisa ser compreendido neste novo momento na perspectiva do desenvolvimento histórico dos direitos humanos, em consonância com a visão de Bobbio (1992, p. 4) no sentido de que "a afirmação dos direitos do homem deriva de uma radical inversão na relação Estado/cidadão ou soberano/súditos, influenciada pelas guerras de religião", através das quais se vai afirmando o direito de resistência à opressão, ou seja, o direito de o indivíduo a não ser oprimido, e a gozar de algumas liberdades fundamentais. Dentre estas se encontra o direito de propriedade, intrinsecamente ligado ao direito à liberdade ou à não intervenção estatal.

Nessa passagem, verifica-se como a questão do direito à liberdade continua presente e atual. Não ficou estagnada no tempo, como um direito de uma época passada. Renovou-se ao assumir um novo conteúdo, composto não mais exclusivamente pela taxativa proibição de intervenção estatal, mas também por imperativos de tutela, na linha do que defende Sen (2000, p. 54) quando fala das "liberdades instrumentais", que seriam aquelas que contribuem, direta ou indiretamente, para as liberdades globais que as pessoas têm para viver como desejariam. Essa metamorfose que permeia o conteúdo da liberdade foi destacada por 


\section{RFD}

Lira (1997, p. 107), redefinindo-se ao longo do tempo em função das circunstâncias históricas, contenção e liberação das forças econômicas.

Lira traz à luz a definição de André Lalande segundo a qual a liberdade pode ser tomada em três sentidos. No sentido geral, liberdade seria "o estado de ser que não sofre constrangimento, agindo conforme a sua vontade, a sua natureza". No sentido político e social a liberdade traduziria a "ausência de uma constrição social imposta ao indivíduo", que é livre para recusar tudo o que a lei não ordena e para fazer tudo o que a lei não veda. Haveria ainda um terceiro sentido, que poderia ser denominado como "psicológico ou moral", segundo o qual a liberdade é o estado do ser que, após refletir em conhecimento de causa, se decide para o bem ou para o mal, realizando em seus atos sua verdadeira natureza. De acordo com estes sentidos, Lira (op. cit., p. 108) conclui que não se pode negar que a liberdade e o direito à terra se ligam como noções indissociáveis.

O solo, conforme destacou Lira, possui "incomensurável valor, tanto para os particulares como para o povo em seu conjunto". Isto porque nele "se radicam a fonte de alimentação das gentes", os elementos indispensáveis para a satisfação das necessidades vitais, a habitação, "as substâncias curativas e de fortalecimento" enfim, conforme a afirmação de Hedeman "o solo é toda hipótese e possibilidade de vida".

A consciência sobre esta ligação entre solo e vida, entre meio ambiente e cosmos, característica da segunda metade do século XX e início do XXI, é que delinearam um novo perfil para a propriedade: outrora um direito de liberdade garantido pela não intervenção do Estado; atualmente vinculado ao dever jurídico de atender à função social e ambiental.

A Constituição em vigor no Brasil considerou tanto o direito de propriedade quanto a defesa do meio ambiente como princípios gerais da atividade econômica, conforme se pode verificar do disposto no artigo 170, em especial nos incisos II e VI. Na opinião de Ferreira (apud. BENJAMIN, 2010, p. 292), essa nova redação parece propor, de forma objetiva, a necessidade de que as imposições resultantes dos deveres de proteção do meio ambiente atendam ao princípio da proporcionalidade, de modo a admitir que a defesa do meio ambiente somente se realiza por meio de medidas de proteção que atendam aos objetivos de segurança ambiental; porém, também permitindo o exercício da atividade econômica. Assim, as medidas de proteção, segundo esta autora, devem ser aquelas que "importem o menor grau de restrição aos demais bens ou direitos envolvidos na relação, e que se demonstrem concretamente necessárias e suficientes para a garantia de proteção esperada". 
Sarmento (1997, p. 52) defende que a intervenção direta do Estado nas relações de direito privado não significa o agigantamento do direito público em detrimento do direito civil; ao contrário: a perspectiva de interpretação civil-constitucional permite que sejam revigorados os institutos de direito civil que estejam defasados da realidade econômica e social contemporânea.

Essa linha de raciocínio também presente no pensamento de Calliess (2001, p. 32) ${ }^{12}$ conduz à conclusão de que os deveres de proteção ao meio ambiente devem ser buscados de forma a evitar o menor grau de restrição possível ao direito de propriedade. Até porque, no caso brasileiro, este direito foi proclamado no artigo $5^{\circ}$, XXII da Constituição Federal de 1988. Não restam dúvidas, portanto, que em decorrência de expressa previsão constitucional, o direito de propriedade continua a ser uma garantia. O que se busca é a compreensão do novo conteúdo desse instituto, em face da disposição contida no inciso XXIII do mesmo artigo $5^{\circ}$, segundo a qual "a propriedade atenderá a sua função social”, e no caput do artigo 225, no sentido de que "todos têm direito ao meio ambiente ecologicamente equilibrado".

O meio ambiente se consolida no meio físico, enquadrado na moldura da propriedade. É nesse palco que o espetáculo da vida se realiza, sem destruí-la ou revogá-la. Assim, a grande diferença entre o passado e o presente é que atualmente "o direito de propriedade aparece ambientalmente qualificado", conforme afirmou Benjamin (2010, p. 294), cuja lição merece ser destacada:

\begin{abstract}
A apropriação dos espaços pela intervenção humana - seja pela ocupação da terra, seja pelo parcelamento do solo e do planejamento urbano das cidades - encontrase condicionada por finalidades e usos que devem ser protegidos. O princípio da função social da propriedade se superpõe à autonomia privada, que rege as relações econômicas, para proteger os interesses de toda a coletividade em torno de um direito ao ambiente ecologicamente equilibrado. Somente a propriedade privada que cumpra sua função social possui proteção constitucional. Por essa razão, seu descumprimento importa a imposição de uma sanção: a expropriação compulsória. Esta é suportada pelo proprietário exatamente em razão do exercício irresponsável do direito e da gestão inadequada dos recursos naturais.
\end{abstract}

Com base nessas reflexões, é possível afirmar que o direito de propriedade continua a ser um direito fundamental, porém vinculado ao dever de cumprir a função social e a

\footnotetext{
${ }^{12}$ A ideia desenvolvida por Calliess (2001, p. 32) de que o Estado deve prestar atenção ao fato de que deve coordenar as esferas de direito dos cidadãos em função de uma máxima liberdade possível, afastando as concepções que possam resultar em uma "ecoditadura" foi utilizada como referencial teórico para o desenvolvimento da seção anterior.
} 
ambiental. Este condicionamento, além de constituir-se em uma obrigação do titular da propriedade, será fiscalizado e gerido pelo Estado de modo a interferir em menor grau possível no direito de propriedade. Em outras palavras, a intervenção do Estado é legítima desde que se dê na medida necessária ao cumprimento da função social e ambiental.

Nessa tarefa de gestão o Estado deve coordenar as esferas de direito dos cidadãos em função de uma máxima liberdade possível, tomando cuidado para que os riscos de dano aos bens individuais fundamentais (dentre os quais o direito de propriedade) não se tornem tão grandes a ponto de transformarem-se em um obstáculo para o próprio Estado de Direito. O papel do Estado, nesse contexto, passa a ser o de gerenciador dos riscos, conforme apontou Giddens (1999, p. 5). Eis que de um lado deve agir para evitar o aprofundamento dos danos coletivos gerados pelo modo de vida contemporâneo (poluição, desmatamento, novas tecnologias etc.) e, de outro, deve esforçar-se para garantir a menor interferência possível nos direitos fundamentais já consagrados.

Nessa direção, faz-se necessária a construção de uma nova perspectiva conceitual para o direito de propriedade, não mais como um direito absoluto, mas como direito/função, conforme vem sendo construído no âmbito do constitucionalismo contemporâneo. Kataoka (2000, p. 465) fala em "direito que permite a um titular usar, gozar e dispor de certos bens, desde que ele o faça de modo a realizar a dignidade da pessoa humana". Um novo conceito de propriedade é preciso, especialmente em decorrência dos sinais de esgotamento do meio ambiente que tornam a tarefa de conservação planetária a mais urgente deste início de século.

\section{CONSIDERAÇÕES FINAIS}

A hipótese formulada no início deste artigo no sentido de que o direito de propriedade continua a ser um direito fundamental foi se confirmando ao longo das pesquisas desenvolvidas para sua elaboração. Porém, deve-se ter em conta que o direito ao meio ambiente ecologicamente equilibrado também adquiriu status de direito fundamental, assim consagrado na maioria das constituições em vigor no Ocidente, razão pela qual quando incidirem tais direitos no caso concreto e estiverem em rota de colisão, será necessário o exercício da ponderação não apenas em uma perspectiva bipolar, como sugerem Dworkin e Alexy, mas sim em uma visão multipolar, na linha da proposta de Calliess (apresentada ao longo deste artigo). 
O direito ao meio ambiente sadio revela-se de tal forma importante que deve ser considerado como verdadeira condição de legitimidade do Estado de Direito, o que não significa, no entanto, que o direito de propriedade possa ser obstado sem uma razão forte o suficiente para justificar a interferência na esfera de liberdade individual do titular da propriedade. Cabe ao Estado o papel de gestor dessa tarefa e à sociedade o dever de zelar contra as possíveis arbitrariedades estatais, a fim de que não se percam as garantias de direitos individuais conquistadas e consolidadas ao longo da história humana.

Os princípios da função social e ambiental da propriedade se superpõem à autonomia privada. Porém, devem incidir in concreto de modo a significar o menor grau possível de interferência e limitação aos direitos individuais. Este monumental desafio está colocado ao poder público e à cidadania neste início de século e vencê-lo pressupõe uma nova forma de lidar com a propriedade privada.

Não se pode perder de vista, com efeito, que o direito de propriedade consiste em um direito de liberdade, conquistado ao longo do tempo como uma garantia do cidadão contra a interferência e arbitrariedade do Estado. E continua a sê-lo. Porém, a propriedade está inserida em um contexto no qual não pode permanecer imune às necessidades de proteção e conservação ambiental.

Demonstrou-se no presente artigo que as constituições em vigor no Ocidente abraçaram a proteção ambiental, atualmente reconhecida dentre o rol dos Direitos Fundamentais de forma inexorável, ante aos sinais de esgotamento dos recursos naturais do planeta Terra. Nesse contexto, o Estado de Direito deve ser também o Estado Ambiental. À propriedade deve ser reconhecido o inevitável perfil ambiental.

\section{REFERÊNCIAS}

ALEMANHA. Lei Fundamental da República Federal da Alemanha (1949). Disponível em: <http://www.gesetze-im-internet.de/bundesrecht/gg/gesamt.pdf>. Acesso em: 10 jan. 2015.

ALEXY, Robert. Teoria dos direitos fundamentais. Trad. Virgílio Afonso da Silva. São Paulo: Malheiros, 2008.

BARROSO, Luís Roberto. Efetividade das normas constitucionais revisitada. Revista de Direito Administrativo, Rio de Janeiro, n. 197, jul./set. 1994. 
BENJAMIN, Antonio Herman de Vasconcellos. Constitucionalização do Ambiente e Ecologização da Constituição Brasileira. In: CANOTILHO, José Joaquim Gomes; LEITE, José Rubens Morato. Direito constitucional ambiental brasileiro. 3. ed. São Paulo: Saraiva, 2010.

BOBBIO, Norberto. A era dos direitos. Rio de Janeiro: Campus, 1992.

CALLIESS, Christian. Rechtsstaat und Umweltstaat: Zugleich ein Beitrag zur Grundrechtsdogmatik im Rahmen mehrpoliger Verfassungsverhältnisse. Tübingen: Mohr Siebeck, 2001.

CANARIS, Claus-Wilhelm. Direitos fundamentais e direito privado. Trad. Ingo Wolfgang Sarlet e Paulo Mota Pinto. São Paulo: Almedina, 2009.

CANOTILHO, José Joaquim Gomes; MOREIRA, Vital. Constituição da República Portuguesa anotada. 3. ed. Coimbra: Coimbra Ed., 1993.

COMPARATO, Fábio Konder. Direitos e deveres fundamentais em matéria de propriedade. In: A questão agrária e a justiça. STROZAKE, Juvelino José (Org.). São Paulo: Editora Revista dos Tribunais, 2000. p. 138-139.

COSTA, Pedro Oliveira da. Apontamentos para uma visão abrangente da função social dos contratos. In: TEPEDINO, Gustavo (Coord.). Obrigações: estudos na perspectiva civilconstitucional. Rio de Janeiro: RENOVAR, 2005.

DERANI, Cristiane. Meio ambiente ecologicamente equilibrado: direito fundamental e princípio da atividade econômica. In: FIGUEIREDO, Guilherme José de. Temas de direito ambiental e urbanístico. São Paulo: Max Limonad, 1988.

DWORKIN, Ronald. Taking Rights Seriously. Harvard: University Press, 1978.

ESPANHA. Constituição (1978). Disponível em:

<www.lamoncloa.gob.es/NR/.../constitucion_ES.pdf>. Acesso em: 14 dez. 2016. 
FRANÇA. Declaração de Direitos do Homem e do Cidadão (1789). Disponível em: $<$ http://www.direitoshumanos.usp.br/index.php/Documentos-anteriores-\%C3\%A0cria\%C3\%A7\%C3\%A3o-da-Sociedade-das-Na\%C3\%A7\%C3\%B5es-at\%C3\%A91919/declaracao-de-direitos-do-homem-e-do-cidadao-1789.html>. Acesso em: 15 nov. 2016.

GIDDENS, Anthony. Risk and responsability. Modern Law Review, v. 62, n. 1, jan. 1999.

HESSE, Konrad. Elementos de direito constitucional da República Federal da Alemanha. Trad. Luíz Afonso Heck. Porto Alegre: Sergio Antonio Fabris Editor, 1998.

KATAOKA, Eduardo Takemi. Declínio do individualismo e propriedade. In: Problemas de Direito Civil-Constitucional. 2000.

LIRA, Ricardo Pereira. Elementos de direito urbanístico. Rio de Janeiro: Renovar, 1997.

MARTIN-RETORTILLO. Regimen constitucional de los derechos fundamentales. In Derechos fundamentales y Constitución. Madrid: Civitas, 1988.

MORAES, Maria Celina Bodin de. A caminho de um direito civil constitucional. Revista de Direito Civil, n. 65, 1993.

NINO, Carlos Santiago. Derecho, moral y política: una revisión de la teoría general del derecho. Barcelona: Editorial Ariel, 1994.

ORGANIZAÇÃO DAS NAÇÕES UNIDAS - ONU. Declaração Universal dos Direitos Humanos, de 10 de dezembro de 1948. Disponível em: <http://www.onu.org.br/img/2014/09/DUDH.pdf>. Acesso em: 14 nov. 2016.

PERLINGIERI, Pietro. Perfis do Direito Civil: introdução ao direito civil constitucional. Trad. Maria Cristina de Cicco. 3. ed. Rio de Janeiro: Renovar, 1997.

PIOVESAN, Flávia. Direitos humanos e o direito constitucional internacional. 3. ed. atual. São Paulo: Max Limonad, 1997.

PRIEUR, Michel. Droit de l'environnement. 5. ed. Paris: Dalloz, 2004. 
RAISER. Il futuro del diritto privato. In: Il compito deldiritto privatto. Trad. Marta Grazadieri. Milão: Giuffré, 1990. p. 32.

RAPOSO, Mário. O direito ao ambiente como direito fundamental. In: Centro de Estudos Judiciários, Textos, Ambiente. Lisboa, 1994.

RODOTÀ, Stefano. Il terribile diritto: studi sulla proprietà privada. Bolonha: Il Mulino, 1990.

SARLET, Ingo Wolfgang. A eficácia dos direitos fundamentais. 2. ed. Porto Alegre: Livraria do Advogado, 2001.

. Direito constitucional ambiental. 3. ed. São Paulo: Revista dos Tribunais, 2013.

SARMENTO, Daniel. Premissas metodológicas para a constitucionalização do Direito Civil. Revista da Faculdade de Direito da UERJ, Rio de Janeiro, n. 5, 1997.

. A normatividade da Constituição e a constitucionalização do Direito Privado.

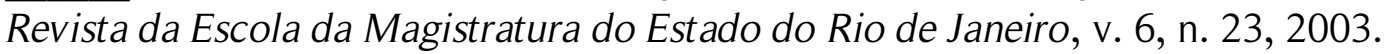

SEN, Amartya. Desenvolvimento como liberdade. Trad. Laura Teixeira Motta. São Paulo: Companhia das letras, 2000.

SOUZA, Sylvio Capanema. Contrato, titulariedade e família: da codificação a constitucionalização. Palestra proferida em evento organizado pela CEPAD, sob a coordenação do professor desembargador Sérgio Cavalieri Filho, 02 mai. 2005. Disponível em: <http://aulascivilconstitucional.blogspot.com.br>. Acesso em: 20 jul. 2016.

TRABUCCHI. Instituzioni di diritto civile. 19. ed. Pádova: Cedam, 1973.

TRINDADE, Antônio Augusto Cançado. Tratado de direito internacional dos direitos humanos. 2. ed. Porto Alegre: SAFE, 2003. v. 1. 